\title{
THE KNIGHT OF THE BURNING PESTLE AND CULTURAL ANAMORPHOSIS
}

Lera Baker Smith

SOME CRITICS CALL the perspective cabinet a curiosity rather than art and view mirror-anamorphoses as either exercises in the mastery of perspective or mere play. ${ }^{1}$ Some may also view Francis Beaumont's The Knight of the Burning Pestle with the same doubts. ${ }^{2}$ However, to look at the seventeenth century and its art forms is to see a culture as it goes through the disruption, distortion, and questioning of its values, its forms, and its social order; it is to observe its people attempting to bring into some kind of rational perspective the jigsaw puzzle that was once a unified picture of the universe. Two works of art based on the problems of perspective-Interior of a Protestant Church (perspective cabinet, Anonymous north Netherlands, ca. 1660) and Descent from the Cross, after Rubens (mirror-anamorphosis, Flemish School, first half of the seventeenth century)-help to reveal both Beaumont's Knight (1613) and the culture it portrays as anamorphic. ${ }^{3}$

Anamorphosis, first of all, is an image distorted so that either a special instrument or a special angle is needed in order to view the image correctly, and the word itself means reformation. ${ }^{4}$ Miriam Milman says, "Trompe-l'oeil is an affirmation of reality, anamorphosis a denial of it." ${ }^{5}$ Here, in the definition of the word itself is the idea that things are not what they seem. In the Descent from the Cross, after Rubens, the viewer has the familiar subject of Christ being removed from the cross. Without the cylindrical mirror, however, the actual painting is an indecipherable blur of general forms and color (see A, Appendix). In spite of the obvious problems in trying to make the painting become recognizable, the viewer finds it compelling to find some way to bring it into focus. Human beings, apparently have a need to order things and disorder is, therefore, unsettling. Milman says that such an anamorphosis "gives the illusion of a non-reality, of a world which has no coherent form and no meaning. . . . [T] he 
results are farthest removed from the representation of reality" (p. 100). There is no doubt that it appears unreal.

If, on the other hand, the viewer simply considers the painting as one way of seeing the world, then perhaps anamorphosis expresses a reality in need of assistance. This painting forces the viewer to use a mirror. In a mirror, the reflection of the painting is a clear image of a representation of the world. As a result, the viewer is put at great distance from the real world. The frame of the canvas reminds the viewer that this is representation, art. Next, he sees an image which is meaningless as it is. The mirror is the third distancing factor and holds a clear representation of the image as this particular artist envisions it, one of many ways of seeing this same event passed on in other representations. This all points to the thing itself which leads to other concrete and abstract associations (e.g, Christ as image). Without the mirror, though, it is all meaningless. This demonstrates the limitations of the eye to perceive accurately everything it sees.

Another kind of anamorphosis is the perspective box (also called the peep show). Interior of a Protestant Church points to the many layers of illusion as well as to the need for a particular viewpoint to correct the distortion. The viewer first sees the trompe l'oeil painting on the outside of the box. The drawers appear to have personal items in them and invite the viewer to see what is in them. Of course, they do not open. The door to the cabinet has a window, and though the door cannot open, it appears to lead to another room. It arouses curiosity and keeps the viewer out simultaneously. The other problem is proportion. While the outside looks real, the idea of a room of such massive proportions being inside or beyond intrigues the viewer and causes him to question what he sees. There seems to be no way to get to the room. It is only visible through the peephole on the right sight of the front panel (Milman, p. 98; also see B, Appendix). Seen through the peephole, the room comes into perspective $(\mathrm{C}, \mathrm{D}$, Appendix). It is the nave of a Protestant church. It is a church with little ornamentation, little furniture, but with ample light. The people are plainly dressed and are in positions of humility, and, compared to the pulpit and lectern, they are small and insignificant. The most ornate object in the room is the chair on which the book sits. Presumably a Bible, it is closed, locked, and chained. Because of the starkness of the room and the featureless, plain people, the eye is drawn again and again to that Bible. It is also the only object that appears to be in reach, and yet it is chained.

This constant teasing of the curiosity only to be frustrated by another layer, another door (or covering) is perplexing. Even the floor tiles each have a symbol which requires interpretation. It is important 
to understand emphasis here. The viewer-once "inside" the cabinet-stands next to the Bible. The Bible looms larger than the people seen in the church. It is full of words to be interpreted and they must be the most important element in the church since the book is, because of perspective, large. It is equal in height to the pulpit, which, though higher, almost rests on the Bible. All the symbols in the floor seem to point toward the Bible. In fact, the Bible seems to stand guard at the door of the church, implying that only this book can give us entry. Yet the words of it are unseen. This might suggest that the book is also a sign, like the signs in the floor, which points to something not actually seen. It is another layer. The perspective box involves us in a process of discovery; the fullness of the painting does not enter the mind all at once, but in stages. Ernest Gilman says of anamorphoses in general that the viewer "is no longer able to see the world unequivocally-with the eye of cool reason-from a secure point of view. Instead he confronts an enigma that demands to be figured out, and his own relationship with the work becomes problematical as it engages him in a process of puzzlement and revelation." 6

Both the mirror-anamorphosis and the perspective box, then, call attention to the work as deception and art, and to the active participation of the viewer; the viewer is forced to question what he sees because he cannot rely on reasoning-the painting cannot be what it appears to be. It is only through some device or viewpoint which limits the actual function or breadth of vision that the art becomes clear.

Just as these painters were experimenting with anamorphosis and trompe l'oeil-perspective and illusion-Francis Beaumont experiments with drama and the perspectives and illusions it can create. The Knight of the Burning Pestle is highly illusionary, heavily layered, and seemingly chaotic and wildly distorted. What appears to be a jumbled mess of color and activity, form and image, if seen with the aid of a "mirror," comes into perspective, forming a picture which resembles reality. Most anamorphoses use one mirror and perspective boxes as many as two peepholes. Beaumont, however, uses three mirrors or peepholes, other than the stage itself, three points of perspective from which to see his play clearly.

The stage as mirror is not new, of course, but the viewer is made highly conscious of the stage as mirror by virtue of the intrusions of the Citizen, his Wife, and Rafe. The interconnectedness of the real audience, the Gentlemen (the audience specified by the Wife), the Citizen and his Wife who sit on stage acting as audience/directors/writers, the stagehands, Rafe, and finally, players in what appears to be the originally plotted play serves to make the audience aware that this play is reflecting within itself and outward to the audience, aware 
of the art form as mirror, lest the audience become too involved. These distancing factors invite the audience to question itself as interpreter, to evaluate its own role in a play. Paradoxically, these distancing factors remove distance between audience and art. Much like the trompe l'oeil techniques used inside the perspective box, this play causes the spectator to "believe that it replaces a certain reality" (Milman, p. 98).

The viewer also uses these various people in the play as points of perspective-like viewing life through peepholes placeing him on different sides of the cabinet of life. Especially important perspective points in the play are Merrythought, Rafe, and the Citizen and his Wife. There are others, but these are the most significant for understanding the play and what it is attempting to do. Whether these characters are termed "peepholes" or "mirrors" is unimportant; they work both ways. These characters act in ways that draw the audience into the play the way peepholes lure one inside the cabinet; and as mirrors, they reflect the ideas of the characters around them. On one side, they are transparent and they present vistas; on the other, they are opaque reflectors in which the viewer sees others and himself.

Beaumont gives direct clues to interpreting the play when George (as Dwarf) addresses Rafe as the mirror of knighthood (II, III). Immediately, there are misreadings of events and people-distorted images. The valley becomes enchanted; Mistress Merrythought interprets Rafe, his Squire, and his Dwarf as giants. With the Burning Pestle, Rafe is the mirror of manhood as well. By the time Rafe and Jasper meet, however, it is evident that the manhood that Rafe mirrors is not his own, but Jasper's manhood. The pestle becomes a worshipped image when Tim calls it the "golden pestle" (II, 313), and Jasper symbolically immasculates him (tears down the idolatrous image of manhood) when he says, "Come, knight, I am ready for you./Now your pestle/Shall try what temper, sir, your mortar's of" (II, 321-23). The stage direction, "Snatches away his pestle," is most important here. Rafe has put his faith in his phallus, and he has been raped. What is so interesting and humorous is the way Jasper intrudes into Rafe's fantasy, hits Rafe with reality, and Rafe remains in the place of Rafe while Rafe runs away.

At this point, the Citizen and his Wife, the third perspective point, reflect on the action. The Wife intends to prevent Rafe being aborted in his heroic deeds by taking the matter to court if necessary (II, 337-40). This speaks to the increasing legal power of the middle class in England. The Wife is losing faith in Rafe (the old heroic ethic) and is replacing honor with power. The Citizen, however, replaces lost faith with magic: "Jasper is enchanted" (II, 342); he misreads the 
mirrored image; it is magic, not real heroism. Rafe also constantly misreads reality for the romantic image that literature of the past creates for him. The inn is, for Rafe, "the most holy order of the Bell" (II, 382), the owner is the knight, and his squires are the bartender, the chamberlain, and the stablehand.

The power of words (literature) is shown in the fact that Jasper, now caught up in the fantasy romance Rafe has created, takes on some of its characteristics. He puts some of his faith in something that is not there. He becomes the hero who rescues his fair lady and actually continues the enchantment motif (Act III). He begins, then, to misread Luce's intentions. She is a siren who has bewitched him and he does not trust her love. He wants a sign of her love. Luce, still in reality, says, "Kill not with thy eyes,/They shoot me through and through. Strike, I am ready;/And, dying, still I love thee" (III, 105-7). Misreading, willful distortion of a sign, is deadly; Luce has faith in Jasper's love. This faith seems to snap Jasper back to reality. When Luce is kidnapped again, she leaves with the image of Jasper as distrustful, murderous, faithless-a false image. Rafe has "raped" the characters of their identity and true sentiment-all through the imaginative power of words.

Rafe is meant to be used in gaining a perspective. Since Rafe is responsible for only part of the play, there must be another way of seeing this. Rafe-who essentially allows the spectator to look at literature, oral and written, literal and figurative, utilitarian and decorative, truthful and deceptive-is balanced by Merrythought, the embodiment of art in the form of music. Rafe accesses faith through words which create false images - the inn, the castle, the monsters. His words become the real thing-a kind of transubstantiation of language. Merrythought, however, has direct faith which is independent of words (IV, 331-77). Though at one point he has nothing left, including bread and wine (a Eucharistic image), he still has joy and can still sing. His faith is not in the visible sign; he believes all will be provided, though unseen. Rafe finally receives food at the tavern, a communion he thinks is free but finds must be paid for. He puts his faith in the fantasy, and it fails him, words fail him, and the Citizen has to pay for him in order to save his life. Rafe and Merrythought create a polarity by which the culture is revealed, a culture which is apparently in chaos, but which in reality is simply shifting emphasis. What is needed, Beaumont seems to say, is a new perspective.

Since Rafe represents an old form of literature, he may also represent a questioning of old forms in religion, literature and art, and in social order. Even Rafe's death is stylized, part of the ritual. It is a symbolic death of empty forms. More important, it is a jarring of 
the comic form $(\mathrm{V}, 299)$. This describes all of his intrusions into the Jasper/Luce story, his raping of the drama.

Rafe is essentially a carte blanche character. He serves the Citizen and his Wife; he becomes whatever he is told to become. As an art formliterature - he is in the hands of the artist. One of the problems with Rafe, however, is that what he acts out does not resemble reality. It is artificial, whimsical. But in all this, he shows us the power of words to transform the impressionable human being.

Rafe also, in his fantasy, attempts to be a hero by means of good deeds; he intends to help Mistress Merrythought, rescue Luce, deliver those in captivity at the castle. Merrythought, however, is not interested in good works. In fact, he does not work at all (I, 379-82, 454-55). As a mirror in this play, Rafe stands as an image in opposition to images of the world around him. They are real; Rafe is an invention, an image created by the Citizen's Wife.

The Citizen and his Wife, though providing only an interlude, are really the most important mirror/perspective point in the play. They are the newly affluent middle class which is attempting to take a prominent place in society (witness the fact that they sit right on the stage, not in the audience). They want power for themselves, that is, the right to have a say in what will be performed; and they want power for their class since they insist that the players "present something notably in honor of the commons of the city" (Introduction, 27-8) and that one of the players be "a citizen, and he shall be of my own trade" (Introduction, 31-2). When honor and courtesy do not work for Rafe, the Citizen and his Wife buy his way out twice so he will not be "beholding" to anyone (III, 180-1; IV, 112-14). Money is a sign of their power and they believe in it.

The Citizen and his Wife also believe in the power of language, even though they are not well educated. They create Rafe's role and the words he says are part of the character. They applaud Rafe when his words sound nice. At the end of Rafe's death scene, the Citizen says that "the boy hath deceived me much; I did not think it had been in him" (V, 174-77). This is a double deception. The Citizen did not have faith in Rafe who demonstrates how grand language can make him, but the words are empty words and have created only fantasy. The Wife's pretentiousness comes out in language also. On the one hand, she is struggling to become better than she is and claims herself to be a gentlewoman, but her language signifies that she is not (III, 582-85). She mirrors for us the use of language as a sign of class distinction and the belief in the sign more than the substance. The one peculiar line the Wife says is, "Ay, George; but yet truth is truth" (I, 413). For one moment she sees through the veil clearly. There is no 
subtle thinking here, but she sees what the Citizen does not and she keeps her faith in Merrythought.

These two characters are the key to the social upheaval going on in England. They emphasize the forms without acquiring the substance of class. They put faith in concrete signs of success-money, power, language, attention, position, control, knowledge. Though none of these is completely under control, the need of the new middle class to control art, language, symbols, and their society is evident. They want to set standards for these things, in spite of the fact that they do not have consistent standards for art (they keep changing Rafe's character and the plot), they still need approval from the "Gentlemen" in the audience, their language shifts between rough and a more proper language, their sense of appropriateness is undeveloped, and their manners (consider the interruptions) need refining.

Merrythought represents substance triumphing over sign. He believes in the thing not seen, in Providence. His faith is in what his song represents - mirth - not in the song itself. He can do without money, food, drink, his wife, his son, but he cannot do without song. Song reminds us of harmony, the music of the spheres, and naturally of God, then. This is a man in harmony with life; he is song itself. To look at Merrythought is to see the art of song itself. This speaks of the inner man and faith. He sees all events through music. It is Merrythought who stands steadfast, unchanging throughout the play. Everyone else is in flux. In the end, he has everyone join in song. He helps to brings Venturewell into harmony with his son, Jasper. Merrythought unifies all aspects of the play. Through him, the fallacy of trusting in any of the good things in this life is made clear. He reflects a classless view of the world. All men become equals with Merrythought. His humility sharpens the view of the others in the play who are pompous, pretentious, and empty. He also reflects the power struggles within the play because he is devoid of any power struggle. He wants nothing but mirth.

If a person trusts only in what he sees (or thinks he sees), he can be deluded. This is the lesson of the peepshow, of anamorphosis, of trompe l'oeil. Human beings need aids to see clearly because they are fooled by realistic illusion. The question comes down to the problem of choosing the right mirror or prism. Beaumont's play addresses this problem. Beaumont questions his society from many angles, through many layers of knowledge. Knowledge and art are in flux as a result of the Reformation, the emergence of the English Church, the splintering of the English Church into separatist groups, frequent changes in state religion, the death of Elizabeth in 1603, the growing rebellion which resulted in a civil war, and the deposing of a king and 
the monarchy itself. It was inevitable that England would look at itself with distorted eyes, with various perspectives, with reservation and attempts at covering up iconoclastic ideas with illusionary tactics which at the same time revealed the truth.

\section{NOTES}

1 Miriam Milman, Trompe-l'oeil Painting (Geneva, Switz.: Editions d'Art Albert Skira S. A., 1982; New York: Rizzoli International Publications, 1983), p. 98; Fred Leeman, Hidden Images, trans. Ellyn Childs Allison and Margaret L. Kaplan (New York: Harry N. Abrams, Inc., 1976), pp. 82-3.

2 Francis Beaumont, The Knight of the Burning Pestle, in The Stuart Period, Vol. II of Drama of the English Renaissance, ed. Russell A. Fraser and Norman Rabkin (New York: Macmillan, 1976), pp. 519-48. Herafter cited in the text by act and line.

3 Interior of a Protestant Church, Plates 76, 77, 78 in Hidden Images, pp. 92-3; this work is also cited as Peepshow Box by Carel Fabritius (1622-54) in Milman, p. 98; Descent from the Cross, after Rubens, in Milman, pp. 100-1.

4 “Anamorphosis," Webster's New Riverside University Dictionary, 1984.

5 Milman, p. 100.

6 Ernest B. Gilman, The Curious Perspective: Literary and Pictorial Wit in the Seventeenth Century (New Haven and London: Yale University Press, 1978), p. 66. 


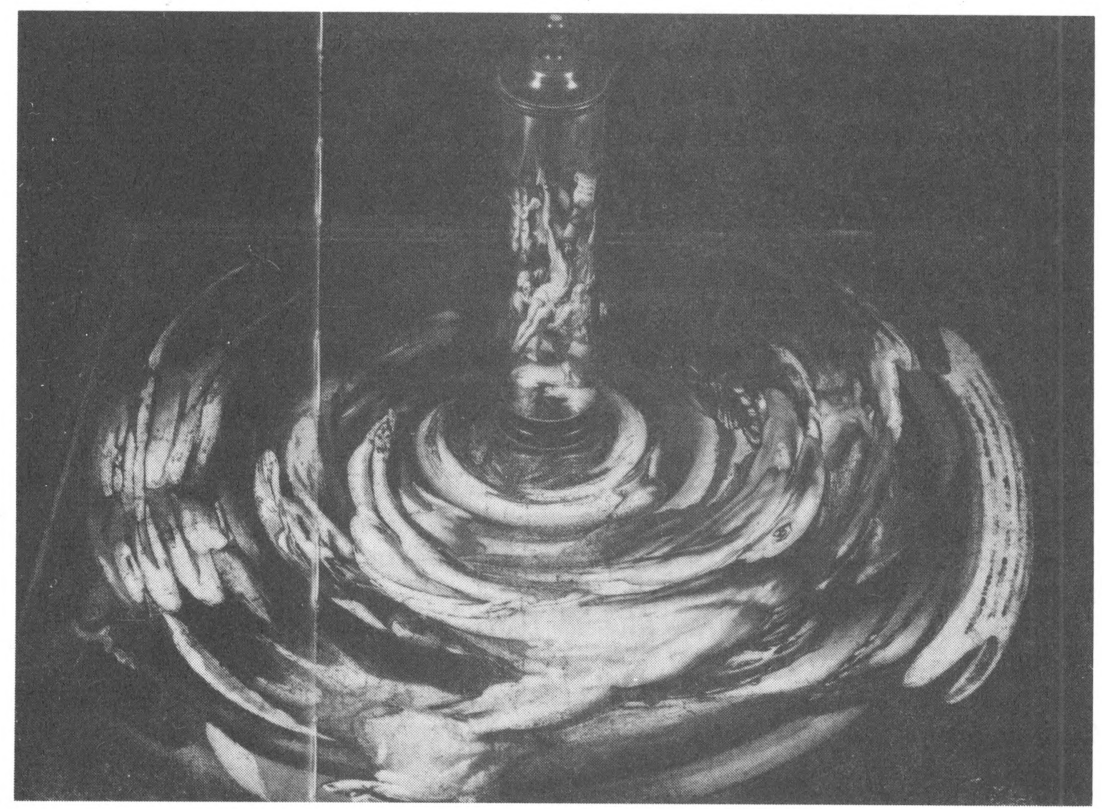

Appendix, A

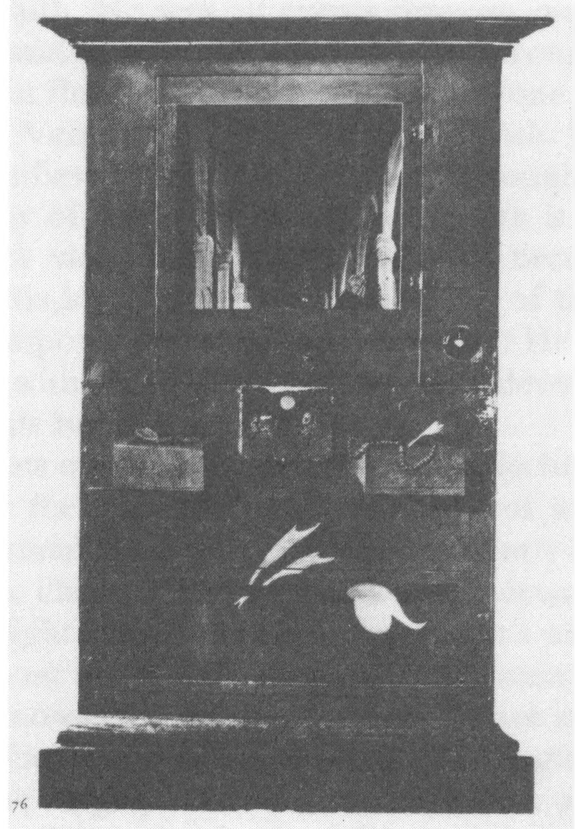

Appendix, $B$ 


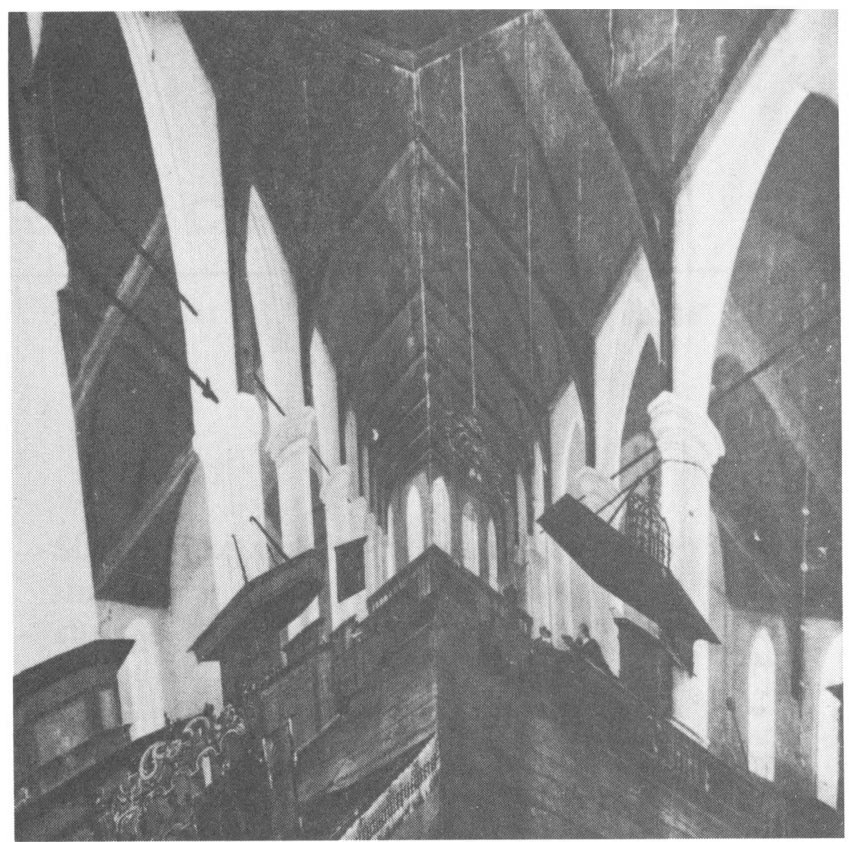

Appendix, $C$

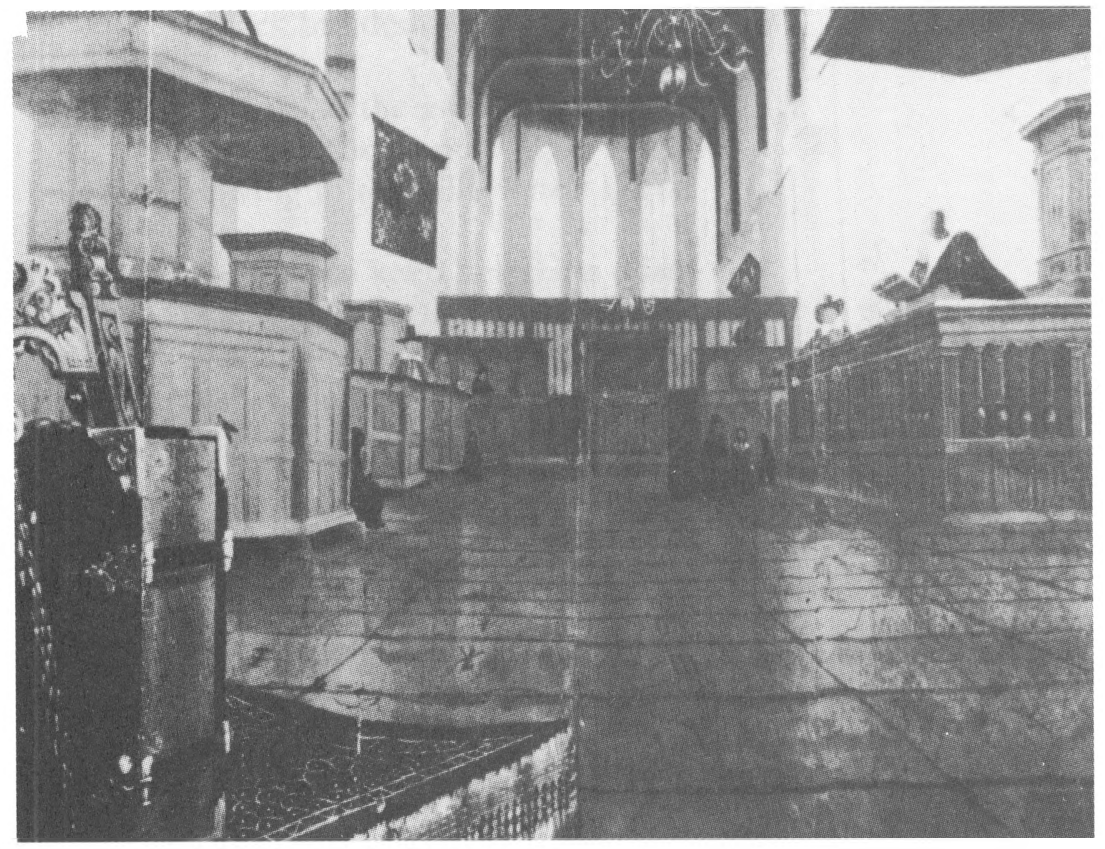

Appendix, $D$ 
